\title{
Phytoplankton Community Responses to Interactions Between Light Intensity, Light Variations, and Phosphorus Supply
}

\author{
Vanessa Marzetz ${ }^{1,2 *}$, Elly Spijkerman ${ }^{1}$, Maren Striebel ${ }^{3}$ and Alexander Wacker ${ }^{2}$ \\ ${ }^{1}$ Ecology and Ecosystem Modeling, Institute of Biochemistry and Biology, University of Potsdam, Potsdam, Germany, \\ ${ }^{2}$ Animal Ecology, Zoological Institute and Museum, University of Greifswald, Greifswald, Germany, ${ }^{3}$ Plankton Ecology, \\ Institute for Chemistry and Biology of the Marine Environment, University of Oldenburg, Wilhelmshaven, Germany
}

\section{OPEN ACCESS}

Edited by:

Patrick J. Neale,

Smithsonian Environmental Research Center (SI), United States

Reviewed by:

Jan Köhler,

Leibniz-Institute of Freshwater Ecology and Inland Fisheries (IGB), Germany

Elena Litchman,

Michigan State University,

United States

*Correspondence:

Vanessa Marzetz

marzetz@uni-potsdam.de

Specialty section: This article was submitted to

Freshwater Science,

a section of the journal

Frontiers in Environmental Science

Received: 02 March 2020 Accepted: 25 November 2020

Published: 16 December 2020

Citation:

Marzetz V, Spijkerman E, Striebel M and Wacker A (2020) Phytoplankton

Community Responses to Interactions

Between Light Intensity, Light Variations, and Phosphorus Supply.

Front. Environ. Sci. 8:539733. doi: 10.3389/fenvs.2020.539733
In a changing world, phytoplankton communities face a large variety of challenges including altered light regimes. These alterations are caused by more pronounced stratification due to rising temperatures, enhanced eutrophication, and browning of lakes. Community responses toward these effects can emerge as alterations in physiology, biomass, biochemical composition, or diversity. In this study, we addressed the combined effects of changes in light and nutrient conditions on community responses. In particular, we investigated how light intensity and variability under two nutrient conditions influence (1) fast responses such as adjustments in photosynthesis, (2) intermediate responses such as pigment adaptation and (3) slow responses such as changes in community biomass and species composition. Therefore, we exposed communities consisting of five phytoplankton species belonging to different taxonomic groups to two constant and two variable light intensity treatments combined with two levels of phosphorus supply. The tested phytoplankton communities exhibited increased fast reactions of photosynthetic processes to light variability and light intensity. The adjustment of their light harvesting mechanisms via community pigment composition was not affected by light intensity, variability, or nutrient supply. However, pigment specific effects of light intensity, light variability, and nutrient supply on the proportion of the respective pigments were detected. Biomass was positively affected by higher light intensity and nutrient concentrations while the direction of the effect of variability was modulated by light intensity. Light variability had a negative impact on biomass at low, but a positive impact at high light intensity. The effects on community composition were species specific. Generally, the proportion of green algae was higher under high light intensity, whereas the cyanobacterium performed better under low light conditions. In addition to that, the diatom and the cryptophyte performed better with high nutrient supply while the green algae as well as the cyanobacterium performed better at low nutrient conditions. This shows that light intensity, light variability, and nutrient supply interactively affect communities. Furthermore, the responses are highly species and pigment specific, thus to clarify the effects of climate change a deeper understanding of the effects of light variability and species interactions within communities is important.

Keywords: phytoplankton communities, light variability, photosynthetic rate, climate change, resource competition, light intensity (irradiance), pigment composition, nutrient supply 


\section{INTRODUCTION}

In a world of climate change, phytoplankton communities face a large variety of challenges due to manifold changes. Rising temperatures, e.g., directly influence many physical and physiological processes (Hatt, 1983; Connelly et al., 2009; GrossWittke et al., 2010; Warren et al., 2012; Pachepsky et al., 2014; Havens et al., 2015; Huang and Chou, 2017). Besides these direct temperature effects on organisms, increasing temperature leads to a phenological shift, i.e., spring starts earlier and summer lasts longer (Stine et al., 2009). Temperate regions are strongly influenced by seasonality and thus are particularly affected by rising temperatures. Rising temperatures lead to shorter or no ice coverage and distinctly altered mixing regimes and periods, such as decreased length of spring vertical mixing followed by increased duration of summer stratification (Vincent, 2009; Wagner et al., 2013; IGB Dossier, 2018). Climate change is also accompanied by more common weather extremes, increased precipitation, and storm events. Higher precipitation is linked to increased terrestrial run-off, thus external inputs of light absorbing dissolved organic material as well as nutrients into lakes (de Wit et al., 2016; Deininger and Frigstad, 2019). More frequent storm events and changes in temperatures will affect the turbidity and biomass production and thus also the light availability. All these manifold changes influence light availability and heterogeneity. The heterogeneity in light conditions in aquatic systems may cause shifts in phytoplankton growth rates (Litchman, 1998), photosynthesis rates (Piccinin, 1976; Marra, 1978; Grobbelaar et al., 1992; Kroon et al., 1992), respiration rates (Beardall et al., 1994; Litchman, 1998), and biochemical composition (Gibson and Foy, 1988; Kroon et al., 1992; Ibelings et al., 1994). All these responses occur on different time scales, e.g., adjusting the electron transport rate (photosynthesis) within milliseconds, whereas building complex biochemical molecules can take several hours. Further, light fluctuations can occur not just seasonally and daily, but in shorter time scales, such as waves that focus light or clouds that shade the water. On one hand, even the shortest light fluctuations influence phytoplankton, as photosynthesis can react very rapidly to light changes (Dromgoole, 1988; Flameling and Kromkamp, 1997; Garcia-Mendoza et al., 2002; Dimier et al., 2009). On the other hand, slower fluctuations affect phytoplankton communities in their composition and diversity (Flöder et al., 2002; Flöder and Burns, 2005) and growth rates (Köhler et al., 2018). In phytoplankton composition changes with the annual succession of a lake, e.g., diatoms dominate in spring, green algae in summer (Salmaso, 2003). Nevertheless, individual species respond very specifically to light intensities and variability (Litchman, 2000; Garcia-Mendoza et al., 2002; Shatwell et al., 2012) and show distinct light reaction curves (unpublished Data). These speciesspecific responses to variability of resource availability in general evolved due to interspecific competition in a community leading to niche partitioning and coexistence (Litchman and Klausmeier, 2001). Competition, adaptation to different light intensities, and the resulting dominance of one species compared to other species might hold a positive effect for the inferior species. For example, a dominating species that can cope with high light intensities might reduce light stress for low light adapted species due to shading. In addition to light adaptation, species have different physiological properties, e.g., size and differential nutrient acquisition rates (Huisman and Weissing, 1995; Dickman et al., 2006; Kerimoglu et al., 2012). Competition within communities is driven by all these factors and thus low light adapted species might not be outcompeted by the high light specialist, if they are able to use nutrients in a more efficient way Thus, within a community different mechanisms can become relevant e.g., physiological plasticity for various light acclimation mechanisms. This could (if possible) be distinguished from the effects caused by phenotypic plasticity of individual species within a community and from the effects caused by species sorting. Competition always influences both, i.e., the physiological processes within the community, which can arise from interactions between light and/or nutrient acquisition. Here we addressed the combined interactions to understand the fundamental implications of all these effects in concert and to examine their relative effects. As different species in communities have a variety of traits, e.g., in utilizing nutrients or light, the species in communities will have different reactions and therefore may overall compensate for environmental variability. This compensation possibly takes place at different temporal scales, as e.g., photosynthesis is a fast response and biomass production a slow response. We hypothesize that (1) photosynthesis at shorter time scales, as well as, (2) pigment concentrations at intermediate time scales change due to light intensity, fluctuations, and nutrients. (3) Communities exposed to fluctuating light show similar slow responses as communities that were constantly exposed to the same mean light intensity. Finally, we hypothesize that (4) light intensity and fluctuations have a larger impact on a community than nutrient (Phosphorus, P) supply.

To test these hypotheses, we carried out laboratory experiments with communities consisting of five phytoplankton species, which were exposed to constant and variable light conditions at different intensities. We evaluated the electron transport rate as measure for the fast photosynthesis response to light changes, phytoplankton pigments concentrations as measure for light response at intermediate time scale, and phytoplankton biomass and community compositions as measure of long-term responses to different light intensities and fluctuations. To test if the nutrient availability influences these phytoplankton responses to light changes, we ran the experiment at high and low nutrient supply.

\section{MATERIALS AND METHODS}

\section{Phytoplankton Cultures}

Five freshwater phytoplankton species were used in this experiment. They were chosen based on taxonomic affiliation and specific traits such as differences in pigment composition, nutrient use, and size.

In detail we used the Cyanophyceae Synechococcus elongatus NÄGELI (Syn, SAG 89.79), the Chlorophyceae Acutodesmus obliquus (TUrpin) Hegewald et Hanagata (Acu, SAG 276-3a), the Bacillariophyceae Stephanodiscus hantzschii 
GRUNOW (Ste, University of Constance), the Cryptophyceae Cryptomonas ovata EHRENBERG (Cry, SAG 979-3), and the Eustigmatophyceae Nannochloropsis limnetica KRIENITZ, HePPERLE, STICH, WEILER, (Nan, SAG 18.99).

Every phytoplankton species was pre-cultured either in high P-supply $\left(50 \mu \mathrm{mol} \mathrm{P} \cdot \mathrm{L}^{-1}\right.$, in the form of $\mathrm{K}_{2} \mathrm{HPO}_{4}$ ) or low P-supply $\left(5 \mu \mathrm{mol} \mathrm{P} \cdot \mathrm{L}^{-1}\right)$ modified Woods Hole MBL medium (Nichols, 1973). To avoid a limitation by potassium in the cultures with a low P-supply, the final concentration of potassium was adjusted to $100 \mu \mathrm{mol} \cdot \mathrm{L}^{-1}$ using potassium chloride. These P-supplies represent commonly found conditions in natural lakes.

\section{Experimental Set Up}

Different species pre-grown as monocultures under controlled laboratory conditions were combined to multi-species communities which were exposed to different $\mathrm{P}$ (high and low) and light conditions (constant and variable). Aliquots of the pre-cultures were used to inoculate the experimental phytoplankton communities with equal carbon (C) shares of each species. A total biomass concentration of $1.67 \mathrm{mg} \mathrm{C} \cdot \mathrm{L}^{-1}$ and $0.67 \mathrm{mg} \mathrm{C} \cdot \mathrm{L}^{-1}$ was established for cultures with high and low P-supply, respectively. Carbon concentrations were estimated using previously determined carbon-light equations based on the extinction at $800 \mathrm{~nm}\left(\mathrm{OD}_{800}\right)$. All experimental phytoplankton cultures were diluted once a day by exchanging $20 \mathrm{~mL}$ of the culture with fresh medium. If variable light conditions were applied as treatments (see below) cultures were diluted at the end of their low light phase and then placed into the high light chamber $\left(0.067 \mathrm{~d}^{-1}\right)$. The cultures were grown in triplicates, at $20^{\circ} \mathrm{C}$ in $500 \mathrm{~mL}$ Erlenmeyer flasks filled with a total volume of $300 \mathrm{~mL}$.

Light treatments consisted of two different light intensities and light conditions (constant and variable). In general, light intensities and light condition treatments in this experiment were chosen based on the common light-optimum curve, going with increasing light intensities from below the compensation point (photosynthesis equals compensation) over a light optimum (highest growth/ photosynthesis) to light inhibition (decrease due to photo damage). The constant light intensities represent possible optimum and near inhibiting light intensities for some of the species (Gervais, 1997; Litchman, 2000). The variable treatments had the same mean light intensity as the constant light treatment, but the cultures were exposed to a combination of light intensities that were either near compensation point and optimum or optimum and inhibiting. The constant light intensities with a regular $12 / 12 \mathrm{~h}$ light/dark cycle were set to 105 or $195 \mu \mathrm{mol}$ photons $\cdot \mathrm{m}^{-2} \cdot \mathrm{s}^{-1}$ using different numbers of fluorescent tubes (FLUORA L30W / 77 and LUMILUX L30W / 830, warm white, Osram AG, München, Germany) and distances to the flasks. Additional darkening foils (neutral density foil filters, Lee Filters, Hampshire, England) were used if necessary. The light intensity was verified with a spherical light sensor (LI-1400 data logger; LI-COR Environmental GmbH, Bad Homburg, Germany, equipped with a $4 \pi$ quantum sensor). Additionally, two variable light conditions were set up, in which phytoplankton communities were irradiated with the same average light intensities as communities exposed to constant light intensities. They were exposed to $3 \mathrm{~h}$ lower light intensity, $6 \mathrm{~h}$ higher light intensity, and again $3 \mathrm{~h}$ of the lower light intensity, which was each shifted by $90 \mu \mathrm{mol}$ photons $\cdot \mathrm{m}^{-2} \cdot \mathrm{s}^{-1}$ in one direction or the other from the mean light intensity. This cycle was followed by $12 \mathrm{~h}$ darkness (Supplementary Figure 1). Consequently, the variability range of the light intensity from low to high light in both variable light treatments was the same, but the mean light intensity was different. The cultures with a high P-supply were harvested after 6 days, whereas the cultures with a low P-supply after 8 days of exponential growth (Supplementary Figure 2). This way a large change in treatment light intensity due to high cell densities was avoided. Additionally low P-supply cultures were expected to grow slower and therefore needed more time to obtain sufficient biomass.

\section{Rapid Light Reaction Curves}

Rapid light reaction curves of each sample were recorded a day before harvesting using the Phytoplankton Analyzer (PhytoPAM, Walz GmbH, Effeltrich, Germany). For the variable treated cultures samples were taken at the end of the first low light intensity phase. $1.6 \mathrm{~mL}$ culture was placed in an all clear glass cuvette. The quantum yield as a reaction to ten different actinic light intensities $(8,32,64,128,192,256,320,384,448$, and $512 \mu \mathrm{mol}$ photons $\cdot \mathrm{m}^{-2} \cdot \mathrm{s}^{-1}$, with an exposure time of $20 \mathrm{~s}$ ) was recorded. It represents a ratio of emitted and absorbed photons, which indicates photosynthetic efficiency. The electron transport rate (ETR), as an indicator for photosynthetic activity, was calculated from the product of the quantum yield, given by the PhytoPAM, and the amount of light emitted to the algae and the constants of 0.84 and 0.5 as optical cross section and light absorption coefficients, respectively (Consalvey et al., 2005; Kromkamp et al., 2008).

The ETR values were fitted against actinic light intensities of the PhytoPAM to interpolate the values for the specific experimental light intensities (Supplementary Figure 3) using the software package R version 3.4.4 (R Development Core Team, 2010). Although, the actinic light does not equal the experimental light conditions completely, due to different bandwidth, we assume the error to be quite similar, as we have used the interpolation for both light intensities in the same way. The ETR value was taken from the curve fit at the growth light intensity. Therefore, it represents the ETR activity of the community at the growth light intensity. The quantum yield of the cultures at growth light intensity was linearly interpolated based on the two light intensities that were higher and lower than the growth light intensity.

\section{Chemical Analysis}

Each phytoplankton culture was analyzed at the end of the experiment (harvesting) for particulate organic carbon (C) and pigments. For carbon analysis, aliquots of the algal suspensions were filtered onto $25 \mathrm{~mm}$ precombusted glass fiber filters (GF /F, Whatman, Dassel, Germany), dried at $50^{\circ} \mathrm{C}$ for $48 \mathrm{~h}$ and analyzed using an elemental analyzer (Euro EA 3000, HEKAtech $\mathrm{GmbH}$, Wegberg, Germany). For pigment analysis, aliquots of the phytoplankton cultures were filtered onto $25 \mathrm{~mm}$ glass 
A

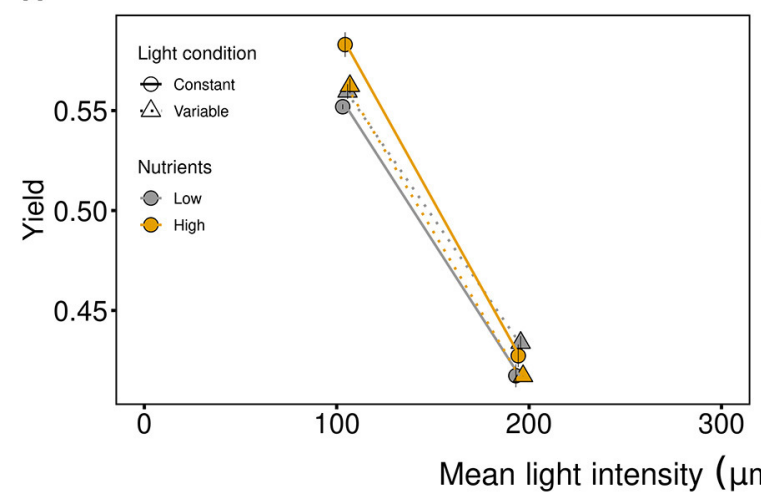

B

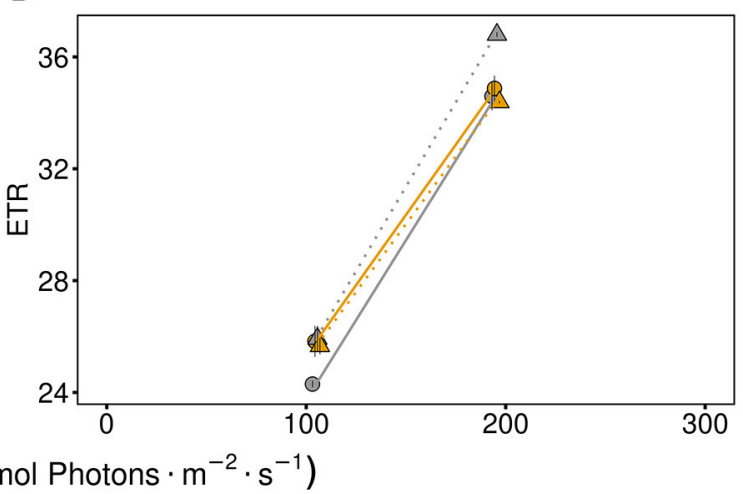

FIGURE 1 | Photosynthetic parameters of the communities: (A) the quantum yield indicating photosynthetic efficiency and (B) the electron transport rate (ETR) as a measure of photosynthetic activity. Communities were either cultivated under variable (triangles, dashed line) or constant (circles, solid line) light conditions. Mean values are shown for high (orange symbols and lines) and low (gray symbols and lines) nutrient supply and are displayed with \pm standard error.

fiber filters (GF/F, Whatman), immediately frozen in liquid nitrogen and stored at $-80^{\circ} \mathrm{C}$. Pigments were extracted in the dark with 90 vol\% ethanol on ice in an ultrasonic bath for $30 \mathrm{~min}$ and stored at $4^{\circ} \mathrm{C}$ overnight. Spectral scans were recorded in a 96 well-plate (Polystyrol, F-bottom type, Boettger, Bodenmais, Germany) in technical triplicates at a spectral absorbance between 300 and $800 \mathrm{~nm}$ in $1 \mathrm{~nm}$ steps (Synergy H1, BioTek Instruments, Winooski, VT, USA). These scans were fitted with a modified Gauss-peak-spectra analysis in R (R Development Core Team, 2010) according to Thrane et al. (2015). For further evaluation pigments were chosen or grouped according to Roy et al. (2011), which resulted in the following pigment parameters and sum parameters: chlorophyll a, b, c, chlorophyll decomposition products, and xanthophylls. These specific pigments were related to the total detected pigment content (called total pigment content hereafter), which resulted in proportions of pigments and pigment groups.

\section{Community Composition}

Phytoplankton species distribution in the communities, cell numbers, and biovolume of the phytoplankton cultures were determined, as during growth species experienced competition and therefore the community composition was expected to be unequal compared to the inoculation. For this, samples from the harvesting day were fixed with Lugol's iodine solution and phytoplankton cells were counted using an inverted light microscope (Thalheim Spezial Optik, Pulsnitz, Germany). The cyanobacterium was counted by epifluorescence microscopy (Axioskop 2, Carl Zeiss, Jena, Germany) under blue light (excitation: BP 450-490 nm; emission: BP 515-565 nm) after staining with acridin-orange (Merck, Darmstadt, Germany). Sizes of phytoplankton cells were measured and converted into biovolume according to Hillebrand et al. (1999). The community composition was calculated based on the cell numbers and biovolume.

\section{Data Analysis}

Effects of nutrient availability (high and low P-supply), average light intensity (105 or $195 \mu \mathrm{mol}$ photons $\cdot \mathrm{m}^{-2} \cdot \mathrm{s}^{-1}$ ), and light condition (constant or variable) on electron transport rate (ETR), pigment composition, biomass (Carbon concentration; C), and species composition were tested using three-way ANOVA.

All statistical analyses were carried out using the statistical software package R (R Development Core Team, 2010).

\section{RESULTS}

Different light intensities, light conditions, and nutrient supplies resulted in distinct responses at different temporal scales. Thereby, photosynthetic activity, pigment composition, and biomass and species composition reflect fast, intermediate, and slow responses.

The fast responding quantum yield and electron transport rate (ETR), used as indicator for photosynthetic efficiency and activity, respectively, were strongly affected by light intensity (Figure 1, Table 1). On one hand, the photosynthetic efficiency decreased at high light intensities (Figure 1A, Table 1). On the other hand, high light intensity and variability favored higher photosynthetic activity (Figure 1B, Table 1). Under low nutrient conditions, the quantum yield and the ETR were higher at variable light conditions at both light intensities (105 $\mu \mathrm{mol}$ photons $\cdot \mathrm{m}^{-2} \cdot \mathrm{s}^{-1}$ and $195 \mu \mathrm{mol}$ photons $\left.\cdot \mathrm{m}^{-2} \cdot \mathrm{s}^{-1}\right)$ compared to constant light conditions (Figure 1, Table 1). Thus, the effect of nutrient concentrations differed between light levels and light conditions (indicated by the significant interaction of light intensity and nutrients as well as light conditions and nutrients, Figure 1).

No significant effect due to any factor was seen at the intermediate response, while the total pigment per carbon (Figure 2A) tended to be lower at high light intensities. Considering specific pigments (examined as the proportion of total pigments), significant adjustments in pigments were observed (Figure 2, Table 1). Light conditions (variability) had 
TABLE 1 | ANOVA table for all factors (light intensity, light condition, and nutrient condition) including interactive effects conducted for all response variables.

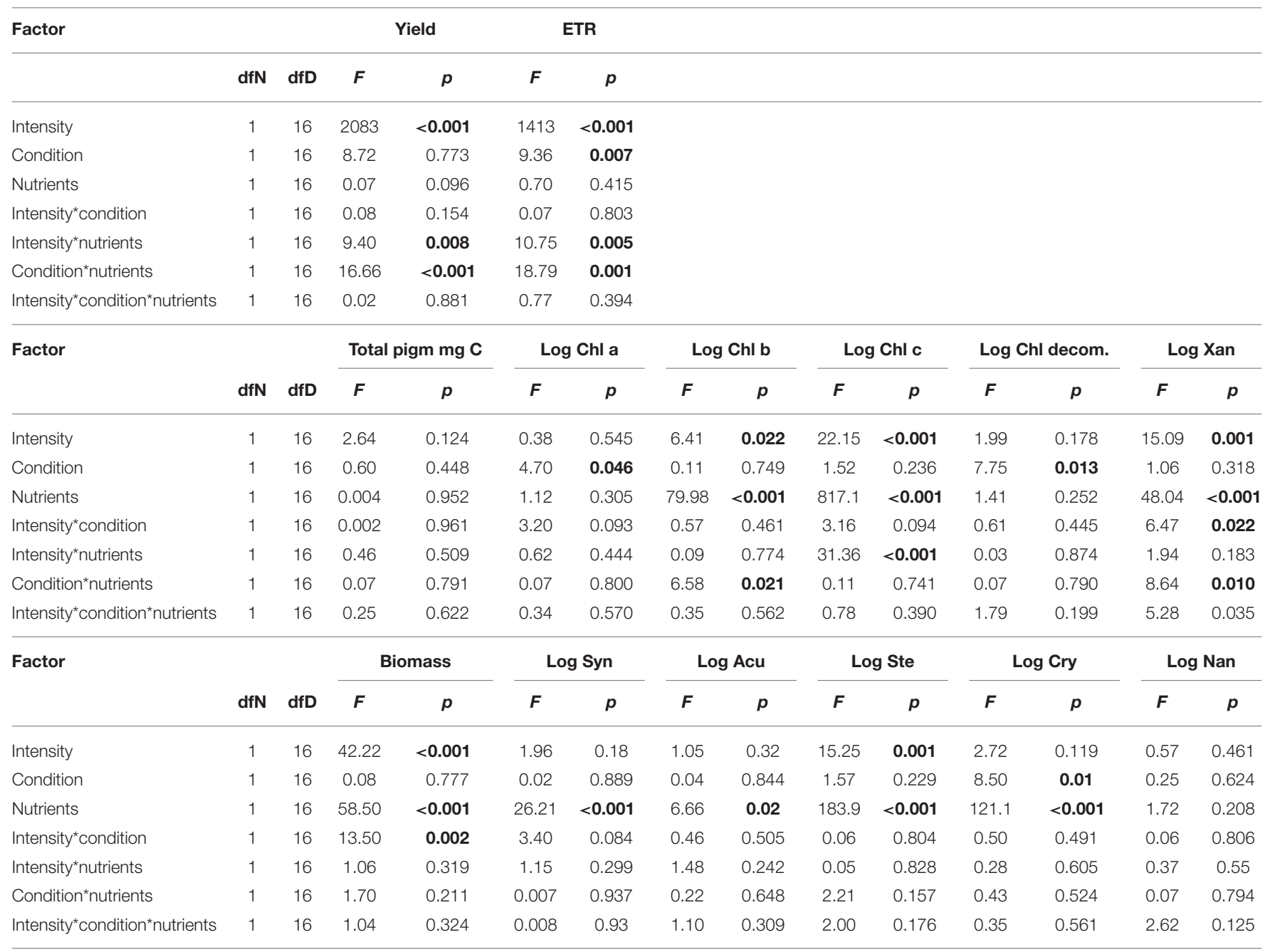

Significant results are shown in bold numbers. Total pigments per mg C represent the sum of the detected pigments in the community based on the community biomass in mg C. Yield, species and pigment proportions were log-transformed before analysis. Yield was not homogenous. Log Acu and Chl c data were not homogeneous and normally distributed. Acronyms are ETR, electron transport rate; total pigm. mg C, total pigment per mg C; Chl, chlorophyll; Chl decom., chlorophyll decomposition products; Xan, xanthophylls; Syn, Synechococcus elongatus; Acu, Acutodesmus obliquus; Ste, Stephanodiscus hantzschii; Cry, Cryptomonas ovata; Nan, Nannochloropsis limnetica.

a significant effect on chlorophyll a proportion (Table 1), resulting in a lower proportion of chlorophyll $a$ under variable light conditions (Figure 2B). Chlorophyll $b$ proportions were significantly higher under low P-supply and even higher at higher light intensity (Figure 2C). Light variability had a positive effect on the proportion of chlorophyll $b$ under limiting nutrient conditions while the effect of light variability was negative (compared to constant conditions) under high nutrient conditions (indicated by the significant interaction term of light conditions and nutrients, Table 1). Chlorophyll $c$ proportions strongly differed between nutrient levels (main effect for nutrients, Table 1) and under low nutrient conditions chlorophyll $c$ proportions were almost zero (Figure 2D). High light intensity resulted in lower proportions of chlorophyll $c$ compared to low light intensity under high nutrient conditions (light intensity and nutrient interaction, Table 1). Chlorophyll decomposition products were higher under variable light conditions, especially if the light intensity was high (Figure 2E, Table 1). This mirrors chlorophyll $a$, which was lowest under variable high light conditions. The proportion of xanthophyll was generally higher with high nutrient supply (Figure 2F, Table 1). While variable light conditions resulted in higher xanthophyll proportions with high nutrient supply, xanthophyll proportions were lower at variable light conditions when exposed to low nutrient concentrations (significant light conditions and nutrient interactive effect, Table 1).

Biomass was significantly higher at higher light intensity and with higher nutrient supply (Figure 3A, Table 1). The effect of light conditions was dependent on the light intensity. At low light intensity the constant light condition treatments were higher while at high light intensity the fluctuating light condition treatments obtained higher biomass (indicated by the light intensity and condition interactive effect, Figure 3A and Table 1). The effects of light intensity, light and nutrient 


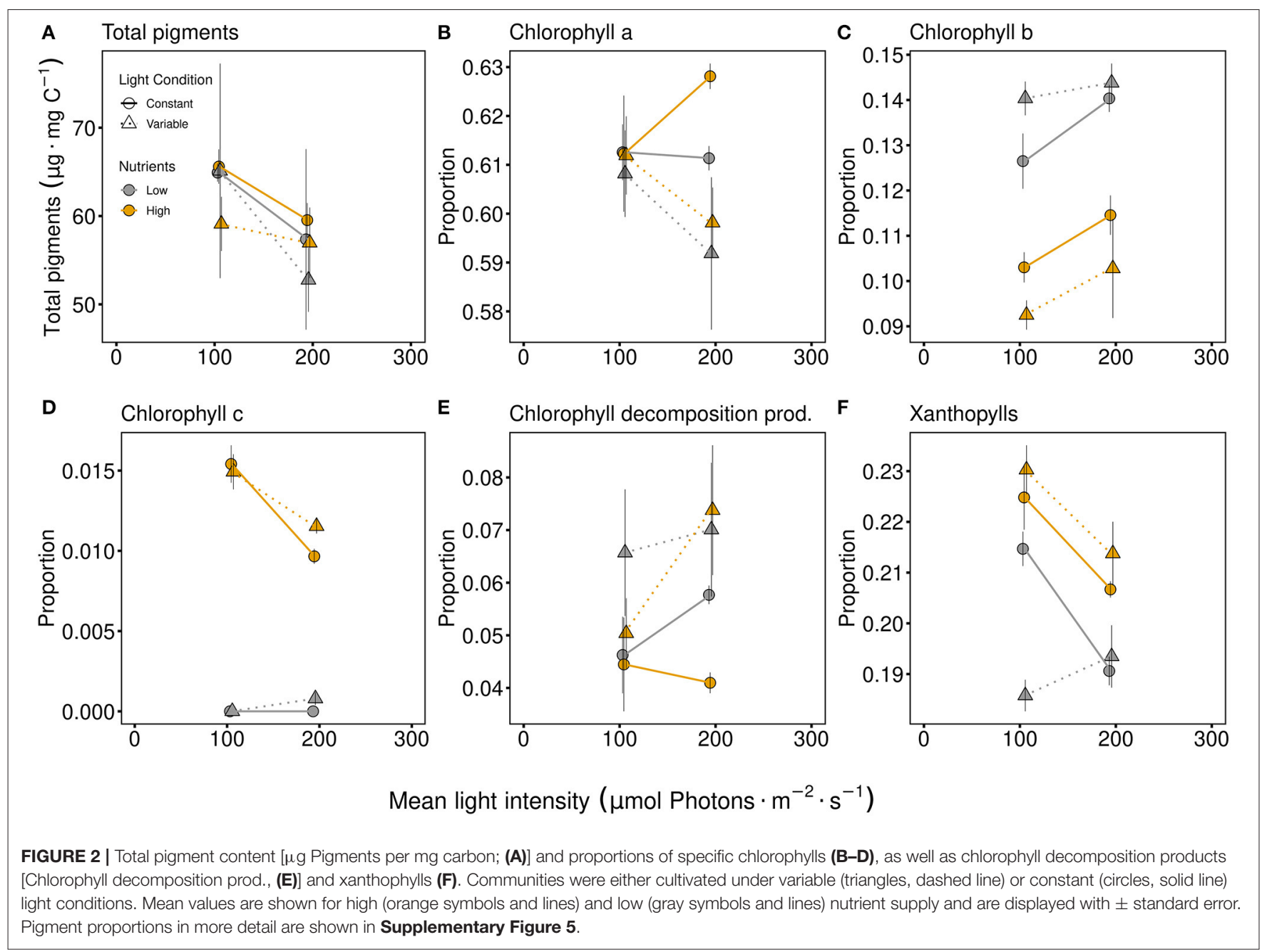

conditions in the community differed between the species. In general, Acutodesmus obliquus was the dominant species in all treatments (Figure 3C). While Synechococcus elongatus and Acutodesmus obliquus were present in higher proportions with low nutrient conditions (Figure 3 and Table 1), Stephanodiscus hantzschii and Cryptomonas ovata had higher proportions under high nutrient conditions (Figure 3 and Table 1) and Nannochloropsis limnetica exhibited no effect from the three factors at all (Table 1). Besides the nutrient effect, Stephanodiscus hantzschii was also affected by light intensity, obtaining higher proportions under low light conditions (Figure 3D, Table 1). The proportion of Cryptomonas ovata differed significantly due to light conditions, thus higher proportions were obtained under constant light conditions (Figure 3E, Table 1).

\section{DISCUSSION}

Photosynthesis as a fast response to light was highly influenced by light intensity and light condition. Although, there was no direct nutrient effect on the quantum yield or the ETR, the significant interaction terms (Table 1) indicated that nutrient supply affected photosynthetic efficiency and activity differently under different light intensities and conditions. This could indicate that under constant light conditions a low supply in nutrients reduces the photosynthetic efficiency and activity compared to fluctuating conditions. In other words, when nutrient supply was low, in addition to a constant light stress the community experienced nutrient stress as well. In this case variability causes light stress relief and resulted in higher shorttime photosynthetic rates. This double stress effect is possibly related to the observation that light energy cannot be used for biomass production when nutrients are lacking (Burson et al., 2018). From monocultures, it has been suggested that variability increased maximum photosynthesis and efficiency as photosynthesis was optimized in fluctuating light (Flameling and Kromkamp, 1997; Talmy et al., 2013).

The total pigment content was not affected by the three factors at intermediate time scales (Figure 2A). However, the factors led to different reactions in specific pigment groups. As pigments are affected by both light intensity (Garcia-Mendoza et al., 2002; Dimier et al., 2009) and variability (Flameling and Kromkamp, 1997) their proportions would generally be expected to show large differences between variable and constant light regimes. Beside the factor of irradiance (Johnsen et al., 1994; Goericke 


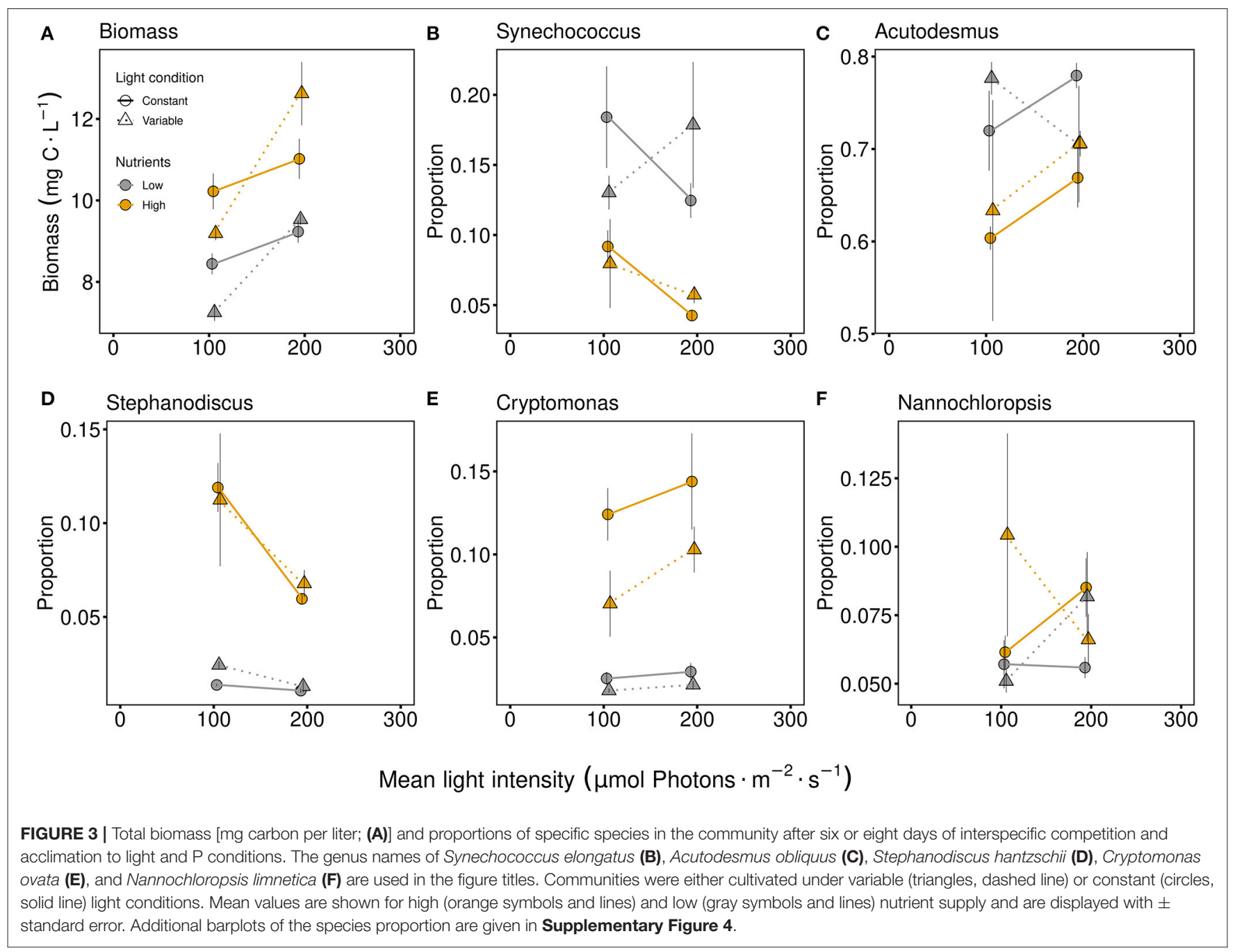

and Montoya, 1998; Schlüter et al., 2000; Henriksen, 2002), the pigment composition of phytoplankton can be additionally affected by day length (Sakshaug and Andresen, 1986), diurnal cycle (Tukaj et al., 2003), or nutrient status (Goericke and Montoya, 1998; Henriksen, 2002). The proportion of the main light harvesting component chlorophyll $a$ was neither affected by light intensity nor nutrient supply and was only affected by light condition (variability). While the proportion of chlorophyll $a$ tended to decrease at high light intensity with fluctuating light conditions, the chlorophyll decomposition products increased. This appears to contradict to the photosynthesis results, as chlorophyll decomposition products can be seen as an indicator for light stress. Due to light stress phytoplankton decrease their concentration of chlorophyll $a$ with high light intensities to protect the photosynthetic machinery against oxygen radical formation (Richardson et al., 1983). Possibly, light variability can be considered stress at high light intensities and stress relief at the lower light intensities. Therefore, the light variability can be relief or stress depending on where the range of the variability lies: at an already higher range, variability can cause stress, as they are varying over high light intensities, whereas at a lower range phytoplankton is receiving periods where the light intensity is much lower than the possible optimum. Another mechanism to increase light harvesting or decrease light stress is the regulation of xanthophylls. For green algae, an up-regulation of the xanthophyll cycle at high light intensities is a mechanisms to redirect excess light energy away from the photosynthetic reaction centers (Garcia-Mendoza et al., 2002; Lavaud et al., 2007; Dimier et al., 2009). In this experiment, the communities generally produced higher xanthophyll proportions at lower light intensities. Besides possible increased light harvesting, this partly can be explained by the higher proportion of the cyanobacterium in these treatments, rather than changes in the xanthophyll cycle. In the xanthophyll cycle the total concentration of xanthophyll would not change, as e.g., diadinoxanthin would change to diatoxanthin, but the overall quantity remains the same. The nutrient supply affected chlorophyll $b$ and chlorophyll $c$ differently. When nutrients were low, communities did not 
contain chlorophyll $c$, but more chlorophyll $b$, suggesting that under low nutrient supply the chlorophyll $b$ containing green algae had a competitive advantage as opposed to the chlorophyll $c$ containing diatom and cryptophyte. This can be confirmed by considering that the nutrient condition affected mainly the community composition. There the green algae generally dominates and is particularly successful at low nutrient supply. Besides nutrient supply, light intensity differently affected chlorophyll $b$ and $c$, chlorophyll $b$ was higher at high light while chlorophyll $c$ was higher at low light intensity. Since we investigated communities, it is difficult to differentiate between regulation of chlorophyll $a$ and $b$ due to light or species composition, as both can affect them. Chlorophyll $c$ can only be related to species composition, which possibly explains the higher proportion in the lower light, as Stephanodiscus hantzschii has a higher proportion in the lower compared to the higher light intensity.

In the slow response of community biomass and composition, we suggest here that phytoplankton communities consisting of different taxonomical groups and associated with different physiological traits were able to compensate for light variability by adjusting their light harvesting mechanisms on the intermediate temporal scale. Communities exposed to constant and fluctuating light conditions behaved predominantly similar in several measures. This was especially prominent for the more slowly changing overall biomass and community composition. There mainly nutrient conditions, and rarely light intensity (for biomass and proportion of the diatom) or condition (only proportion of the cryptophyte) had a large impact, contrastingly to the fast reacting process of photosynthesis. We assume that the effects of variability were compensated by different traits of specific taxonomic groups and species, testing monocultures in addition to the community could strengthen this assumption. For example, significantly distinct light requirements can be found in different algal classes (Gibson and Foy, 1982; Richardson et al., 1983; Kana and Glibert, 1987; Huisman and Weissing, 1995; Gervais, 1997; Flameling and Kromkamp, 1998; Litchman, 2000; Schwaderer et al., 2011; Wacker et al., 2015). Different taxonomic groups differ in their antenna organization and pigment composition, which leads to differences in light utilization efficiencies (Kunath et al., 2012). Yet, neither light intensity nor condition strongly affected the community composition in our current experiment. Only Stephanodiscus hantzschii and Cryptomonas ovata decreased in their proportion due to light intensity and condition, respectively. Here, light fluctuated in shorter intervals of $3 \mathrm{~h}$ low light, $6 \mathrm{~h}$ high light, and $3 \mathrm{~h}$ low light followed by $12 \mathrm{~h}$ darkness. Larger interval lengths of several days have been shown to positively influence stable coexistence (Litchman and Klausmeier, 2001) and species diversity of a phytoplankton community (Flöder et al., 2002; Litchman et al., 2015). However, even shorter intervals ( $20 \mathrm{~min}$ ) have been shown to allow stable coexistence and even showed that light acquisition traits can be changed, indicating high plasticity of cyanobacteria (Guislain et al., 2019). However, interval length as well as the average irradiance has been shown to influence growth (Litchman, 2000), partially because algae show a high degree of acclimation to light (Dimier et al., 2009). With respect to the overall biomass, this was also valid here, since biomass increased with higher light intensity and was additionally positively affected by light variability. At the lower mean light intensity the biomass of the communities experiencing variability decreased compared to ones grown in constant light, which can be due to light varying over an irradiance range of limiting to saturating light intensities (Litchman, 2000) and a general lower growth efficiency caused by light variation (Köhler et al., 2018). On one hand, fluctuating over a higher mean light intensity could be advantageous for the algae, while being temporarily relieved from the inhibiting light intensity they were able to recover from light stress, which would explain the increase in biomass due to fluctuations. On the other hand varying over lower light intensities can have caused some species to be below their light compensation point (Gervais, 1997; Litchman, 2000), resulting the light period effectively available for growth to be shortened. Therefore, the requirements of single species matter, which influence nutrient and light competitive abilities of communities (Huisman and Weissing, 1995).

In our experiment, the interplay between nutrient supply and light as a resource was additionally dependent on the light condition, i.e., if constant or fluctuating. As phytoplankton communities are subjected to temporal light variations ranging from seconds to hours or days that are overlaid on the diurnal cycle of light (Steele, 1985; Grobbelaar, 1989) the interplay of these factors is of high importance at all temporal scales. In surface mixed layers, the light environment of phytoplankton is modified and the cells may be rapidly moved across a large light gradient from very high intensities to darkness (MacIntyre et al., 2000; Dimier et al., 2009; Köhler et al., 2018). These rapid changes modify photosynthesis of the community, but over several days, pigment and biomass production could remain at an intermediate level, especially because different species are complementary in their light use. Thus, the effect of light variability could be seen in two different ways: (1) Communities do have the capability of compensating and therefore maintain similar values in species composition (except for the cryptophyte) and biomass to the constant counterpart and (2) variability is possibly even needed to sustain diverse communities due to niche partitioning.

Changes in light variability, light intensity, and nutrients are expected to become more and more important as lakes are affected by climate change. Climate change effects such as increasing mean temperature leads to a phenological shift (Stine et al., 2009) and results in changed mixing regimes and periods (Wagner et al., 2013; Selmeczy et al., 2019). In addition to these indirect effects on light and nutrient conditions, shifts in precipitation and more extreme weather events causes direct changes in light and nutrient regimes (IBG ed., Vincent, 2009). Many studies have shown effects of one or two factors influencing single species (Gibson and Foy, 1982; Dimier et al., 2009) or communities (Marra, 1978; Köhler et al., 2018) while investigating either photosynthesis (Flameling and Kromkamp, 1997; Garcia-Mendoza et al., 2002), growth (Litchman, 2000; Burson et al., 2018), or diversity (Flöder et al., 2002). Our approach demonstrates that better knowledge on the effects of variability and intensity of light coupled with nutrient supply is 
important to understand the effect on community physiology, biomass, and composition.

\section{DATA AVAILABILITY STATEMENT}

The datasets generated for this study are available on request to the corresponding author.

\section{AUTHOR CONTRIBUTIONS}

VM and AW designed the experiment and wrote the first draft and all authors contributed substantially to later versions of the manuscript. VM performed the experiment. VM and MS did the chemical/biochemical analysis. All authors analyzed the data.

\section{REFERENCES}

Beardall, J., Burger-Wiersma, T., Rijkeboer, M., Sukenik, A., Lemoalle, J., Dubinsky, Z., et al. (1994). Studies on enhanced post-illumination respiration in microalgae. J. Plankton Res. 16, 1401-1410. doi: 10.1093/plankt/16.10.1401

Burson, A., Stomp, M., Greenwell, E., Grosse, J., and Huisman, J. (2018). Competition for nutrients and light: testing advances in resource competition with a natural phytoplankton community. Ecology 99, 1108-1118. doi: 10.1002/ecy.2187

Connelly, S. J., Moeller, R. E., Sanchez, G., and Mitchell, D. L. (2009). Temperature effects on survival and DNA repair in four freshwater cladoceran Daphnia species exposed to UV radiation. Photochem. Photobiol. 85, 144-152. doi: 10.1111/j.1751-1097.2008.00408.x

Consalvey, M., Perkins, R. G., Paterson, D. M., and Underwood, G. J. C. (2005). Pam Fluorescence: a beginners guide for benthic diatomists. Diatom Res. 20, 1-22. doi: 10.1080/0269249X.2005.9705619

de Wit, H. A., Valinia, S., Weyhenmeyer, G. A., Futter, M. N., Kortelainen, P., Austnes, K., et al. (2016). Current browning of surface waters will be further promoted by wetter climate. Environ. Sci. Technol. Lett. 3, 430-435. doi: 10.1021/acs.estlett.6b00396

Deininger, A., and Frigstad, H. (2019). Reevaluating the role of organic matter sources for coastal eutrophication, oligotrophication, and ecosystem health. Front. Mar. Sci. 6:144. doi: 10.3389/fmars.2019.00210

Dickman, E. M., Vanni, M. J., and Horgan, M. J. (2006). Interactive effects of light and nutrients on phytoplankton stoichiometry. Oecologia 149, 676-689. doi: 10.1007/s00442-006-0473-5

Dimier, C., Brunet, C., Geider, R., and Raven, J. (2009). Growth and photoregulation dynamics of the picoeukaryote Pelagomonas calceolata in fluctuating light. Limnol. Oceanogr. 54, 823-836. doi: 10.4319/lo.2009.54. 3.0823

Dromgoole, F. I. (1988). Light fluctuations and the photosynthesis of marine algae. II. Photosynthetic response to frequency, phase ratio and amplitude. Funct. Ecol. 2, 211-219. doi: 10.2307/2389697

Flameling, I. A., and Kromkamp, J. (1997). Photoacclimation of Scenedesmus protuberans (Chlorophycea) to fluctuating irradiances simulating vertical mixing. J. Plankton Res. 19, 1011-1024. doi: 10.1093/plankt/19.8.1011

Flameling, I. A., and Kromkamp, J. (1998). Light dependence of quantum yields for PSII charge separation and oxygen evolution in eucaryotic algae. Limnol. Oceanogr. 43, 284-297. doi: 10.4319/lo.1998.43.2.0284

Flöder, S., and Burns, C. W. (2005). The influence of fluctuating light on diversity and species number of nutrient-limited phytoplankton. J. Phycol. 41, 950-956. doi: 10.1111/j.1529-8817.2005.00124.x

Flöder, S., Urabe, J., and Kawabata, Z. I. (2002). The influence of fluctuating light intensities on species composition and diversity of natural phytoplankton communities. Oecologia 133, 395-401. doi: 10.1007/s00442-002-1048-8

\section{FUNDING}

This study was supported by the German Research Foundation (WA2445/10-1) and the Open Access Publishing Fond of the University of Potsdam.

\section{ACKNOWLEDGMENTS}

We thank Silvia Heim, Sabine Hergt, and Caroline Maik for experimental assistance, Svenja Schälicke for comments on the manuscript, and Aaron Katz for English corrections.

\section{SUPPLEMENTARY MATERIAL}

The Supplementary Material for this article can be found online at: https://www.frontiersin.org/articles/10.3389/fenvs. 2020.539733/full\#supplementary-material

Garcia-Mendoza, E., Matthijs, H. C. P., Schubert, H., and Mur, L. R. (2002). Non-photochemical quenching of chlorophyll fluorescence in Chlorella fusca acclimated to constant and dynamic light conditions. Photosyn Res. 74, 303-315. doi: 10.1023/A:1021230601077

Gervais, F. (1997). Light-dependent growth, dark survival, and glucose uptake by Cryptophytes isolated from a freshwater chemocline. J. Phycol. 33, 18-25. doi: 10.1111/j.0022-3646.1997.00018.x

Gibson, C. E., and Foy, R. H. (1982). Photosynthetic characteristics of planktonic blue-green algae: the response of twenty strains grown under high and low light. Br. Phycol. J. 17, 169-182. doi: 10.1080/00071618200650171

Gibson, C. E., and Foy, R. H. (1988). "The significance of growth rate and storage products for the ecology of Melosira italica ssp. subarctica in Lough Neagh," in Algae and The Aquatic Environment, ed F. E. Round (Bristol: Biopress), 88-106.

Goericke, R., and Montoya, J. P. (1998). Estimating the contribution of microalgal taxa to chlorophyll a in the field-variations of pigment ratios under nutrient- and light-limited growth. Mar. Ecol. Prog. Ser. 169, 97-112. doi: 10.3354/meps169097

Grobbelaar, J. U. (1989). Do light/dark cycles of medium frequency enhance phytoplankton productivity? J. Appl. Phycol. 1, 333-340. doi: 10.1007/BF00003470

Grobbelaar, J. U., Kroon, B. M. A., Burger-Wiersma, T., and Mur, L. R. (1992) Influence of medium frequency light/dark cycles of equal duration on the photosynthesis and respiration of Chlorella pyrenoidosa. Hydrobiologia 238, 53-62. doi: 10.1007/BF00048773

Gross-Wittke, A., Gunkel, G., and Hoffmann, A. (2010). Temperature effects on bank filtration: redox conditions and physical-chemical parameters of pore water at Lake Tegel, Berlin, Germany. J. Wat. Clim. Chan 1, 55-66. doi: $10.2166 /$ wcc. 2010.005

Guislain, A., Beisner, B. E., and Köhler, J. (2019). Variation in species light acquisition traits under fluctuating light regimes: implications for non-equilibrium coexistence. Oikos 128, 716-728. doi: 10.1111/oik. 05297

Hatt, H. (1983). Effect of temperature on the activity of the amino acid receptors in the crayfish walking leg. J. Comp. Physiol. 152, 405-409. doi: 10.1007/BF00606245

Havens, K. E., Pinto-Coelho, R. M., Beklioglu, M., Christoffersen, K. S., Jeppesen, E., Lauridsen, T. L., et al. (2015). Temperature effects on body size of freshwater crustacean zooplankton from Greenland to the tropics. Hydrobiologia 743, 27-35. doi: 10.1007/s10750-014-2000-8

Henriksen, P. (2002). Effects of nutrient-limitation and irradiance on marine phytoplankton pigments. J. Plankton Res. 24, 835-858. doi: $10.1093 /$ plankt/24.9.835

Hillebrand, H., Dürselen, C. D., Kirschtel, D., Pollingher, U., and Zohary, T. (1999). Biovolume calculation for pelagic and benthic microalgae. J. Phycol. 35, 403-424. doi: 10.1046/j.1529-8817.1999.3520403.x 
Huang, W.-P., and Chou, L.-S. (2017). Temperature effects on life history traits of two sympatric branchiopods from an ephemeral wetland. PLOS ONE 12:e0179449. doi: 10.1371/journal.pone.0179449

Huisman, J., and Weissing, F. J. (1995). Competition for nutrients and light in a mixed water column: a theoretical analysis. Am. Nat. 146, 536-564. doi: $10.1086 / 285814$

Ibelings, B. W., Kroon, B. M. A., and Mur, L. R. (1994). Acclimation of photosystem II in a cyanobacterium and a eukaryotic green alga to high and fluctuating photosynthetic photon flux densities, simulating light regimes induced by mixing in lakes. New Phytol. 128, 407-424. doi: 10.1111/j.1469-8137.1994.tb02987.x

IGB Dossier (2018). Lakes Under Climate Change Diagnosis and Prognosis From Long- Term Research. Berlin: Leibniz-Institute of Freshwater Ecology and Inland Fisheries. doi: 10.4126/FRL01-006410415

Johnsen, G., Samset, O., Granskog, L., and Sakshaug, E. (1994). In vivo absorption characteristics in 10 classes of bloom-forming phytoplankton: taxonomic characteristics and responses to photoadaptation by means of discriminant and HPLC analysis. Mar. Ecol. Prog. Ser. 105, 149-157. doi: 10.3354/meps105149

Kana, T. M., and Glibert, P. M. (1987). Effect of irradiances up to $2000 \mu \mathrm{E}$ $\mathrm{m}-2 \mathrm{~s}-1$ on marine Synechococcus WH7803-II. Photosynthetic responses and mechanisms. Deep Sea Res. Part I Oceanogr. Res. Pap. 34, 497-516. doi: 10.1016/0198-0149(87)90002-1

Kerimoglu, O., Straile, D., and Peeters, F. (2012). Role of phytoplankton cell size on the competition for nutrients and light in incompletely mixed systems. J. Theor. Biol. 300, 330-343. doi: 10.1016/j.jtbi.2012.01.044

Köhler, J., Wang, L., Guislain, A., and Shatwell, T. (2018). Influence of vertical mixing on light-dependency of phytoplankton growth. Limnol. Oceanogr. 63, 1156-1167. doi: 10.1002/lno.10761

Kromkamp, J. C., Dijkman, N. A., Peene, J., Simis, S. G. H., and Gons, H. J. (2008). Estimating phytoplankton primary production in Lake IJsselmeer (The Netherlands) using variable fluorescence (PAM-FRRF) and C-uptake techniques. Eur. J. Phycol. 43, 327-344. doi: 10.1080/09670260802080895

Kroon, B. M. A., Burger-Wiersma, T., Visser, P. M., and Mur, L. R. (1992). The effect of dynamic light regimes on Chlorella II. Minimum quantum requirement and photosynthesis-irradiance parameters. Hydrobiologia 238, 79-88. doi: 10.1007/BF00048776

Kunath, C., Jakob, T., and Wilhelm, C. (2012). Different phycobilin antenna organisations affect the balance between light use and growth rate in the cyanobacterium Microcystis aeruginosa and in the cryptophyte Cryptomonas ovata. Photosyn. Res. 111, 173-183. doi: 10.1007/s11120-011-9715-4

Lavaud, J., Strzepek, R. F., and Kroth, P. G. (2007). Photoprotection capacity differs among diatoms: Possible consequences on the spatial distribution of diatoms related to fluctuations in the underwater light climate. Limnol. Oceanogr. 52, 1188-1194. doi: 10.4319/lo.2007.52.3.1188

Litchman, E. (1998). Population and community responses of phytoplankton to fluctuating light. Oecologia 117, 247-257. doi: 10.1007/s0044200 50655

Litchman, E. (2000). Growth rates of phytoplankton under fluctuating light. Freshw. Biol. 44, 223-235. doi: 10.1046/j.1365-2427.2000. 00559.x

Litchman, E., and Klausmeier, C. A. (2001). Competition of phytoplankton under fluctuating light. Am. Nat. 157, 170-187. doi: 10.1086/318628

Litchman, E., Klausmeier, C. A., and Bossard, P. (2015). Phytoplankton nutrient competition under dynamic light regimes. Limnol. Oceanogr. 49, 1457-1462. doi: 10.4319/lo.2004.49.4_part_2.1457

MacIntyre, H. L., Kana, T. M., and Geider, R. J. (2000). The effect of water motion on short-term rates of photosynthesis by marine phytoplankton. Trends Plant Sci. 5, 12-17. doi: 10.1016/S1360-1385(99)01504-6

Marra, J. (1978). Phytoplankton photosynthetic response to vertical movement in a mixed layer. Mar. Biol. 46, 203-208. doi: 10.1007/BF00 390681

Nichols, H. W. (1973). "Culture methods and growth measurements," in Handbook of Phycological Methods. Culture Methods and Growth Measurements, ed J. R. Stein (Cambridge: Cambridge University Press), 7-24.

Pachepsky, Y. A., Blaustein, R. A., Whelan, G., and Shelton, D. R. (2014). Comparing temperature effects on Escherichia coli, Salmonella, and Enterococcus survival in surface waters. Lett. Appl. Microbiol. 59, 278-283. doi: $10.1111 /$ lam.12272
Piccinin, B. B. (1976). Photosynthesis by natural phytoplankton populations and its interrelationship with light and temperature. (Master thesis). McMaster University, Hamilton, Ontario, Canada.

R Development Core Team. (2010). R: A Language and Environment for Statistical Computing. Vienna, Austria: R Foundation for Statistical Computing. Available online at: http://www.r-project.org

Richardson, K., Beardall, J., and Raven, J. A. (1983). Adaption of unicellular algae to irradiance: an analysis of strategies. New Phytol. 93, 157-191. doi: 10.1111/j.1469-8137.1983.tb03422.x

Roy, S., Llewellyn, C. A., Egeland, E. S., and Johnsen, G. (2011). Phytoplankton Pigments: Characterization, Chemotaxonomy and Applications in Oceanography. Cambridge: Cambridge University Press. doi: 10.1017/CBO9780511732263

Sakshaug, E., and Andresen, K. (1986). Effect of light regime upon growth rate and chemical composition of a clone of Skeletonema costatum from the Trondheimsfjord, Norway. J. Plankton Res. 8, 619-637. doi: $10.1093 /$ plankt/8.4.619

Salmaso, N. (2003). Life strategies, dominance patterns and mechanisms promoting species coexistence in phytoplankton communities along complex environmental gradients. Hydrobiologia 502, 13-36. doi: 10.1023/B:HYDR.0000004267.64870.85

Schlüter, L., Møhlenberg, F., Havskum, H., and Larsen, S. (2000). The use of phytoplankton pigments for identifying and quantifying phytoplankton groups in coastal areas:testing the influence of light and nutrients on pigment/chlorophyll a ratios. Mar. Ecol. Prog. Ser. 192, 49-63. doi: 10.3354/meps 192049

Schwaderer, A. S., Yoshiyama, K., Tezanos Pinto, P., Swenson, N. G., Klausmeier, C. A., and Litchman, E. (2011). Eco-evolutionary differences in light utilization traits and distributions of freshwater phytoplankton. Limnol. Oceanogr. 56, 589-598. doi: 10.4319/lo.2011.56.2.0589

Selmeczy, G. B., Abonyi, A., Krienitz, L., Kasprzak, P., Casper, P., Telcs, A., et al. (2019). Old sins have long shadows: climate change weakens efficiency of trophic coupling of phyto- and zooplankton in a deep oligo-mesotrophic lowland lake (Stechlin, Germany)-a causality analysis. Hydrobiologia 831, 101-117. doi: 10.1007/s10750-018-3793-7

Shatwell, T., Nicklisch, A., and Köhler, J. (2012). Temperature and photoperiod effects on phytoplankton growing under simulated mixed layer light fluctuations. Limnol. Oceanogr. 57, 541-553. doi: 10.4319/lo.2012.57.2.0541

Steele, J. H. (1985). A comparison of terrestrial and marine ecological systems. Nature 313, 355-358. doi: 10.1038/313355a0

Stine, A. R., Huybers, P., and Fung, I. Y. (2009). Changes in the phase of the annual cycle of surface temperature. Nature 457, 435-440. doi: 10.1038/nature07675

Talmy, D., Blackford, J., Hardman-Mountford, N. J., Dumbrell, A. J., and Geider, R. J. (2013). An optimality model of photoadaptation in contrasting aquatic light regimes. Limnol. Oceanogr 58, 1802-1818. doi: 10.4319/lo.2013.58.5.1802

Thrane, J. E., Kyle, M., Striebel, M., Haande, S., Grung, M., Rohrlack, T., et al. (2015). Spectrophotometric analysis of pigments: a critical assessment of a high-throughput method for analysis of algal pigment mixtures by spectral deconvolution. PLoS ONE 10:e0137645. doi: 10.1371/journal.pone.0137645

Tukaj, Z., Matusiak-Mikulin, K., Lewandowska, J., and Szurkowski, J. (2003). Changes in the pigment patterns and the photosynthetic activity during a light-induced cell cycle of the green alga Scenedesmus armatus. Plant Physiol. Biochem. 41, 337-344. doi: 10.1016/S0981-9428(03)00028-7

Vincent, W. F. (2009). "Effects of Climate Change on Lakes," in Encyclopedia of Inland Waters, G. E. Likens (Amsterdam: Elsevier), 55-60. doi: 10.1016/B978-012370626-3.00233-7

Wacker, A., Piepho, M., and Spijkerman, E. (2015). Photosynthetic and fatty acid acclimation of four phytoplankton species in response to light intensity and phosphorus availability. Eur. J. Phycol. 50, 288-300. doi: 10.1080/09670262.2015.1050068

Wagner, A., Hülsmann, S., Horn, W., Schiller, T., Schulze, T., Volkmann, S., et al. (2013). Food-web-mediated effects of climate warming: consequences for the seasonal Daphnia dynamics. Freshw. Biol. 58, 573-587. doi: 10.1111/j.1365-2427.2012.02809.x

Warren, D. R., Robinson, J. M., Josephson, D. C., Sheldon, D. R., and Kraft, C. E. (2012). Elevated summer temperatures delay spawning and reduce redd construction for resident brook trout (Salvelinus fontinalis). Glob. Chang. Biol. 18, 1804-1811. doi: 10.1111/j.1365-2486.2012.02670.x 
Conflict of Interest: The authors declare that the research was conducted in the absence of any commercial or financial relationships that could be construed as a potential conflict of interest.

The handling editor is currently organizing a Research Topic with one of the author MS, and confirms the absence of any other collaboration.
Copyright (C) 2020 Marzetz, Spijkerman, Striebel and Wacker. This is an open-access article distributed under the terms of the Creative Commons Attribution License (CC $B Y)$. The use, distribution or reproduction in other forums is permitted, provided the original author(s) and the copyright owner(s) are credited and that the original publication in this journal is cited, in accordance with accepted academic practice. No use, distribution or reproduction is permitted which does not comply with these terms. 